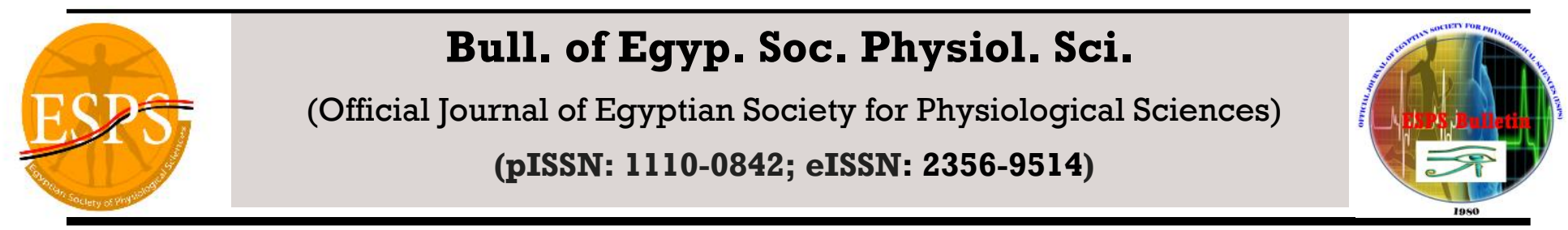

\title{
Effect of Erythropoietin on Metabolic and Contractile Functions of Soleus Muscle in Type I Diabetic Rats
}

\author{
Gehan A. Shaker, Reem M. Emam, Refka K. Messiha, and Hanaa A. Abd-El-moneim \\ Department of Medical Physiology/ Faculty of Medicine/Mansoura University, Mansoura, Egypt
}

Received: 1 Jan 2018

Accepted: 27 Feb 2018

Available online: 1 June 2018

\section{Keywords}

- Erythropoietin (EPO)

- GLUT4

- STZ-induced DM

- Rats

\begin{abstract}
Diabetes mellitus has been linked with specific morphological and metabolic abnormalities in skeletal muscle in a fiber specific manner. Erythropoietin (EPO) is a glycoprotein hormone that regulates the development of erythrocytes through binding to a high affinity receptor expressed in erythroid progenitor cells. EPO receptor expression in non hematopoietic tissue, including skeletal muscle progenitor cells, raises the possibility of a role for EPO beyond erythropoiesis. So the aim of the present study was to evaluate the effect of EPO on skeletal muscle changes as a complication of type 1 diabetes mellitus in STZ- rat experimental model. Methods: 40 male Sprague Dawely rats were divided into 5 groups : control group, diabetic group (STZ-induced, $50 \mathrm{mg} / \mathrm{kg}$ I.P.), insulin treated diabetic ; (received $0.75 \mathrm{IU} / 100 \mathrm{~g}$ body weight daily, S.C; for 4 weeks), EPO treated diabetic; (received EPIAO® S.C , 200 I.U/Kg, 3 times weekly, day after day for 4 weeks),and insulin and EPO treated diabetic groups. At the end of the experiments, fasting blood glucose, insulin levels, lipid profile, contractile changes in soleus muscle and glucose transporter 4 (GLUT4) expression in soleus muscle were evaluated. Results: All biochemical parameters were improved in the group treated with insulin or EPO with greater improvement in insulin treated group. The greatest improvement was in the group treated with combined insulin and EPO. Contractile function of soleus muscle in diabetic group showed significant decrease in muscle tension either before or after fatigue, significant decrease in time taken to reach complete fatigue, significant increase in time taken to reach peak and in time taken to relax to $50 \%$ when compared with normal group. All parameters were improved in insulin treated and EPO treated groups, with greater improvement in insulin treated group. The greatest improvement was in combined insulin and EPO treated group. The reduced GLUT 4 expression in diabetic soleus muscle was significantly increased in insulin treated group as compared to EPO treated group, however combined EPO and insulin treated group showed greater increase in GLUT4 expression. Conclusion: The present results showed that, EPO injection improved hyperglycemia, hypoinsulinemia, hyperlipidemia, and skeletal muscle changes observed in STZinduced diabetes in rats. Therefore, EPO could be beneficial in managing diabetic disorders and the application of EPO in treatment of diabetes can be considered.
\end{abstract}

Corresponding author: Dr. Gehan A. Shaker, Physiology department, Faculty of Medicine, Mansoura University. Tel: 01066020009. Email: dr.gehanshaker911@gmail.com 


\section{Introduction}

Diabetes mellitus has been linked with specific morphological and metabolic abnormalities in skeletal muscle in a fiber specific manner. The reduction in absolute force production in T1DM may be explained by a fiber type-specific atrophy, as slow-twitch or type I fibers exhibit minimal loss or a slight gain in fiber area, while fast-twitch fibers, especially the fatigable glycolytic (type IIB) fibers, exhibit the most severe atrophy (1).

Hyperglycemia has a negative effect on skeletal muscle as it leads to proteins glycation and further oxidation reactions that leads to advanced glycation end products (AGE) which have been implicated in the pathophysiology of the aging process, and are clearly established as contributing to the other T1DM-related complications (2). Fasttwitch/type II myosin fibers are the most affected by AGE (3). Previous studies demonstrated that fast-twitch/type II myosin fibers commonly exhibit atrophy and loss of contractile function in various models of T1DM (4). Hyperglycemia possibly affects skeletal muscle through activation of the polyol pathway, leading to tissue damage by reducing cellular defenses against oxidative stress (5). DM is also associated with rapid down regulation of GLUT4 which is the major insulinresponsive glucose transporter, and is widely responsible for insulin-stimulated glucose transport into muscle and adipose tissues (6).

Erythropoietin (EPO), a hypoxia-responsive glycoprotein hormone produced mainly by the kidney, is the primary regulator for erythroid differentiation. It acts by binding to a high affinity receptor on the surface of erythroid progenitor cells to promote survival, proliferation, and differentiation. However, EPO receptor expression extends beyond the hematopoietic progenitor cells that include the cardiovascular system, neural progenitors and neurons, and skeletal muscle progenitor cells ( $7 \& 8)$. Mice lacking EpoR die in utero from severe anemia and exhibit many developmental defects in heart and brain, including decreased progenitor cell proliferation and increased apoptosis (9) .

Previous studies have revealed that EPO exerts multiple protective effects, including antioxidative (10\& 11), anti-inflammatory (12\& 13) and anti-apoptotic effects (14). It has been suggested that EPO could have a positive effect on skeletal muscle regeneration, growth, oxidative capacity and angiogenesis(15). In clinics, EPO is widely used in diabetic patients receiving hemodialysis, and this application established the need for critical exploration of the interplay between EPO and glucose homeostasis (16).

Based on this background, the present study was designed to explore whether EPO therapy can reduce metabolic and contractile changes in soleus muscle in STZ-induced Type 1 DM rat model.

\section{Material and Methods}

\section{Experimental animals:}

Fourty Sprague Dawely male rats, weighting 150$200 \mathrm{~g}$ were included. The study was conducted at the Medical Experimental Research Center (MERC), Mansoura faculty of medicine. The study protocol was approved by the local ethics committee for animal experiments, Mansoura faculty of medicine. The animals were kept at a 
standard animal care environment and fed with standard animal food.

\section{Chemicals:}

Erythropoietin (EPIAO)®: is a recombinant human erythropoietin, manufactured by Shenyang sunshine pharmaceutical co.,Ltd. It is available in a vial $1.0 \mathrm{ml}$ colorless transparent solution, with pH 6.9 \pm 0.5 ., and 2000IU/vial. It should be stored at $2-8{ }^{\circ} \mathrm{C}$ and avoid direct sunshine .

Streptozotocin( STZ) : was purchased from Sigma (St. Louis, MO, USA) ; 1 gm powder, Stored at $-20 \mathrm{c}$, away from dry air and moisture, dissolved in cold citrate buffer PH $4.5(0.9 \mathrm{gm}$ citric acid and $1.47 \mathrm{gm}$ sodium citrate in $100 \mathrm{ml}$ saline), Insulin mixtard 30:( Novo Nordisk, Denmark) $100 \mathrm{IU} / \mathrm{ml}$ Suspension for injection in a vial. containg $10 \mathrm{ml}$ is equivalent to $1000 \mathrm{IU}$.

\section{Experimental groups:}

Animals were divided into $\mathbf{5}$ groups, $(\mathbf{n}=\mathbf{8}$ in each group):

Group I: control group, were injected with 0.75 $\mathrm{ml}$ normal saline subcutaneous (S.C) once daily for 4 weeks. Group II: Diabetic group: Rats were injected with $0.75 \mathrm{ml}$ normal saline S.C once daily for 4 weeks. Group III:Diabetic insulin treated Group: (D+insulin ) : Rats were injected S.C with mixtard insulin $30,0.75 \mathrm{IU} / 100 \mathrm{~g}$ body weight (17) once daily for 4 weeks. Injection was started 48 hours after induction of diabetes. GroupIV : Diabetic EPO group: (D+ EPO): Diabetic rats were injected with EPO in a a dose of ( 200 I.U/Kg body weight S.C, 3 times weekly, day after day) (18) for 4 weeks. Injection was started 48 hours after induction of diabetes. Group V : Diabetic Insulin-EPO group: (D+ insulin +EPO) :Rats were treated with insulin and EPO with the same doses in groups III and IV.

\section{Experimental Model: (Type 1 DM)}

For induction of type 1 diabetes: Overnight fasted rats were intraperitonealy (IP) injected with with streptozotocin (STZ; $50 \mathrm{mg} / \mathrm{kg}$, single injection) dissolved in $0.1 \mathrm{mmol} / \mathrm{L}$ citrate buffer (19). One week later, blood samples were used to determine fasting blood glucose (FBG) and insulin levels. Hyperglycemia and hypoinsulinemia were used to identify the success of the model. Animals with FBG $>300 \mathrm{mg} / \mathrm{dl}$ were included in the study (20). After STZ injection, rats were allowed to drink $10 \%$ glucose solution to prevent hypoglycemia (21). FBG was measured weekly during the whole experimental period with an Accu- check Go strip test using glucometer.

\section{Collection of blood and tissue samples}

At the end of experimental protocol, Rats were anethesitised with thiopental (I.P, $120 \mathrm{mg} / \mathrm{kg}$ ). Blood was collected from the heart., left to coagulate and centrifuged at $3000 \mathrm{rpm}$ for 30 minutes .Separated serum was stored at $-20^{\circ} \mathrm{C}$ for biochemical analysis. Tissue samples: Soleus muscle on one side was separated and broken down into small cubes,weighting 30mg. Cubes was stored immediately into cryotubes (RNasefree), then stored at liquid nitrogen at $-196^{\circ} \mathrm{C}$ to prevent RNA destruction to be ready for PCR technique. Soleus muscle on the other side was hold by a thread attached to its distal tendon to the force transducer of the biopac apparatus and immersed in krebs solution( $120 \mathrm{mM} \mathrm{NaCl}, 25 \mathrm{mM}$ 
NaHco3, 1.2mM NaH2Po4, 1.2 mM MgSo4, 5.0 $\mathrm{mM} \mathrm{Kcl}, 2.5 \mathrm{mM}$ calcium gluconate, $11.5 \mathrm{mM}$ glucose) at $30^{\circ} \mathrm{C}$. It was continuously bubbled with $5 \% \mathrm{CO} 2,95 \% \mathrm{O} 2$, and the $\mathrm{pH}$ was kept at 7.4. Specimen can be kept in $-20^{\circ} \mathrm{C}$ to preserve . Serum - coagulation at room temperature 10-20 mins, then centrifugation $20 \mathrm{~min}$ at the speed of 2000-3000 r.p.m.

\section{Biochemical assessment:}

-Fasting blood glucose was measured by the glucose oxidase method . Lipid profile: Triglycerides, cholesterol, HDL, LDL, were determined. All kits were manufactured by Spinreact company.

-Insulin level was determined by using rat insulin ELISA kit, manufactured in Sun red biological technology company, was purchased from biogene company (REF).

\section{Measurement of GLUT 4 expression:}

PCR was carried out in clinical pathology department, Mansoura university. kits was purchased from Thermo scientific company, lot 00269687. It was stored at $-20^{\circ} \mathrm{C}$.

Primers used: According to gene bank, primers sequences were:

\begin{tabular}{|c|c|c|c|c|c|}
\hline Gene & $\begin{array}{l}\left(5^{\prime}-3^{\prime}\right) \\
\text { forward } \\
\text { primer }\end{array}$ & $\begin{array}{l}\left(5^{\prime}-3^{\prime}\right) \\
\text { reverse } \\
\text { primer }\end{array}$ & $\begin{array}{l}\text { Base } \\
\text { pairs }\end{array}$ & $\begin{array}{l}\text { Anne } \\
\text { aling } \\
\text { temp } \\
\text { eratu } \\
\text { re }{ }^{\circ} \mathrm{C}\end{array}$ & $\begin{array}{l}\text { Cyc } \\
\text { le } \\
(S)\end{array}$ \\
\hline $\begin{array}{l}\text { GLUT } \\
4 \\
\text { (SLc2a } \\
4)\end{array}$ & $\begin{array}{l}\text { GAAACG } \\
\text { CAAGTT } \\
\text { GGAAAG } \\
\text { A }\end{array}$ & $\begin{array}{l}\text { CTACTA } \\
\text { AGAGCA } \\
\text { CCGAGA } \\
\text { CC }\end{array}$ & 225 & 55 & 30 \\
\hline B-actin & $\begin{array}{l}\text { GCCAAC } \\
\text { CGTGAA } \\
\text { AAGATG }\end{array}$ & $\begin{array}{l}\text { CCAGGA } \\
\text { TAGAGC } \\
\text { CACCAA } \\
\mathrm{T}\end{array}$ & 681 & 57 & 30 \\
\hline
\end{tabular}

These primers gene were manufactured in BIOSEARCH TECHNOLOGIES company. DNA molecular weight marker type 50 bp DNA ladder was applied to identify the size of the PCR products.The ladder was purchased from Thermo scientific ,Lot 00145906 , concentration $0.1 \mu \mathrm{g} / \mu \mathrm{l}$ (22).

\section{Contractile changes in the soleus muscle:}

BIOPAC was used determining the optimal force range for the experiment (force transducer 100 for soleus muscle).

\section{Statistical analysis:}

Data were analysed by SPSS software ver. 17 (IBM, US). The findings were expressed as the mean \pm SD. Statistical analyses were undertaken using independent One-way ANOVA with posthoc tukey test. The t-test was used for two sample assuming unequal variances, which confirmed the statistically significant difference $(\mathrm{p}<0.05)$. A Pvalue $<0.05$ was accepted statistically significant.

\section{Results}

As shown in table (1), insulin treatment produced significant decrease in FBG $(\mathrm{P}=0.0001)$. Also EPO produced significant decrease in FBG $(\mathrm{P}=0.0001)$ and non significant increase in insulin $(\mathrm{P}=0.099)$. Combined treatment with insulin and EPO significantly decreased FBG ( $P=0.0001)$, and non significant increase in fasting insulin $(\mathrm{P}=0.225)$ when compared with diabetic group Also in table (2) ,Insulin treatment produced significant decrease in cholesterol $(\mathrm{P}=0.0001)$, triglycerides $(\mathrm{P}=0.0001), \mathrm{LDL}(\mathrm{P}=0.0001)$, and significant increase in HDL $(\mathrm{P}=0.049)$ when compared to diabetic group. Also, EPO treatment 
produced significant decrease in cholesterol $(\mathrm{P}=0.0001), \quad$ triglycerides $\quad(\mathrm{P}=0.0001), \quad \mathrm{LDL}$ $(\mathrm{P}=0.0001)$, but non significant increase in $\mathrm{HDL}$ $(\mathrm{P}=0.099)$ when compared to diabetic group. Combined treatment with insulin and EPO produced significant decrease in cholesterol $(\mathrm{P}=0.0001), \quad$ triglycerides $\quad(\mathrm{P}=0.0001), \quad$ LDL $(\mathrm{P}=0.0001)$, and significant increase in HDL $(\mathrm{P}=0.0001)$ when compared to diabetic group.

\section{Contractile functions:}

Data was obtained by analysis of the recorded curves .In table (3), diabetic animals showed significant decrease in muscle tension either before or after fatigue $(\mathrm{P}=0.0001)$, significant decrease in time taken to reach complete fatigue $(\mathrm{P}=0.0001)$ that means rapid fatigue. However time taken to reach peak and time taken to relax 50\% were significantly increased $(\mathrm{P}=0.0001)$ as compaired to control.

Diabetic rats treated with insulin, showed significant increase in muscle tension before fatigue $(\mathrm{P}=0.0001)$ and insignificant increase in tension after fatigue $(\mathrm{P}=0.933)$. Significant increase in time taken to reach complete fatigue was also observed $(\mathrm{P}=0.0001)$, Also significant decrease in time to reach peak and time to reach $50 \%$ relaxation was observed $(\mathrm{P}=0.0001)$ as compared to diabetic non treated group.

EPO treatment also produced significant increase in muscle tension before fatigue $(\mathrm{P}=0 . .027)$ and insignificant increase in tension after fatigue $(\mathrm{P}=0$. .927). Significant increase in time taken to reach complete fatigue was also observed $(\mathrm{P}=0.007)$. significant decrease in time to reach peak and time to reach $50 \%$ relaxation was observed $(\mathrm{P}=0.0001)$ as compared to diabetic non treated group.

Combined treatment of diabetic rats with insulin and EPO by the same doses produced more significant increase in muscle tension before fatigue $(\mathrm{P}=0.0001)$ and insignificant increase in tension after fatigue $(\mathrm{P}=0.067)$. significant increase in time taken to reach complete fatigue $(\mathrm{P}=0.0001)$ and Significant decrease in time to reach peak and time to reach $50 \%$ relaxation was observed $(\mathrm{P}=0.0001)$ when compared to diabetic non treated group. From the tables, we can find that ,the greater improvements of diabetic changes was obtained in combined insulin and EPO treated group.

\section{PCR ( area ratio) (GLUT4 expression ratio):}

Data was obtained by analysis of PCR bands by image $\mathbf{j}$ program. As shown in fig.(1), (2), (3); The decreased GLUT4 expression In STZdiabetic model is significantly reversed $(\mathrm{P}=0.0001)$ with insulin treatment. Also EPO treatment by the same previous doses significantly increased GLUT4 ( $\mathrm{P}=0.0001)$. Combined treatment of diabetic rats with insulin and EPO produced more significant increase in GLUT4 expression when compared to diabetic non treated group $(\mathrm{P}=0.0001)$. 
Table (1) Effect of insulin, EPO, and combined treatment on the level of fasting blood glucose (FBG), and fasting insulin in type 1 diabetic rats:

\begin{tabular}{|c|c|c|c|c|l|}
\hline $\begin{array}{c}\text { Groups } \\
\mathbf{N = 8}\end{array}$ & $\begin{array}{c}\text { control } \\
\text { (G:I) }\end{array}$ & $\begin{array}{c}\text { (D.M) } \\
\text { (G:II) }\end{array}$ & $\begin{array}{c}\text { D.M+I } \\
\text { (G:III) }\end{array}$ & $\begin{array}{c}\text { D.M +EPO } \\
\text { (G:IV) }\end{array}$ & $\begin{array}{l}\text { D.M+I+EPO } \\
\text { (G:V) }\end{array}$ \\
\hline $\begin{array}{c}\text { fasting } \\
\text { blood } \\
\text { glucose } \\
\text { (mg/dl) }\end{array}$ & $92.77 \pm 10.23$ & $386.48 \pm 14.41^{*}$ & $237.87 \pm 13.47 * \#$ & $278.87 \pm 10.62^{* \# \$}$ & $178.62 \pm 17.64 * \# \$ \neq$ \\
\hline $\begin{array}{c}\text { fasting } \\
\text { insulin } \\
\text { (mIU/L) }\end{array}$ & $11.39 \pm 4.587$ & $7.22 \pm 1.720^{*}$ & $8.65 \pm 2.673$ & $7.216 \pm 1.216^{*}$ & $10.071 \pm 1.643$ \\
\hline
\end{tabular}

Results are expressed as mean \pm SD. Significance means $p<0.05$.

(*) significant as compared to control. (\#) significant as compared to D.M.

(\$) significant as compared to D.M+I. ( $\quad(\neq)$ significant as compared to D.M +EPO

Table (2) Effect of insulin, EPO, and combined treatment on the level of cholesterol, triglycerides, LDL, and HDL in type 1 diabetic rats:

\begin{tabular}{|c|c|c|c|c|c|}
\hline $\begin{array}{r}\text { Groups } \\
\text { N=8 }\end{array}$ & $\begin{array}{c}\text { control } \\
\text { (G:I) }\end{array}$ & $\begin{array}{c}\text { diabetic } \\
\text { (D.M) } \\
\text { (G:II) }\end{array}$ & $\begin{array}{l}\text { D.M+I } \\
\text { (G:III) }\end{array}$ & $\begin{array}{c}\text { D.M +EPO } \\
(\mathrm{G}: I V)\end{array}$ & $\begin{array}{c}\text { D.M+I+EPO } \\
(G: V)\end{array}$ \\
\hline $\begin{array}{c}\text { Cholesterol } \\
(m g / d l)\end{array}$ & $\begin{array}{l}148.18 \pm 14.5 \\
8\end{array}$ & $\begin{array}{l}372.43 \pm 17.01 \\
*\end{array}$ & $\begin{array}{l}250.25 \pm 8.18 \\
* \#\end{array}$ & $\begin{array}{l}312.00 \pm 15.44^{*} \# \\
\$\end{array}$ & $198.93 \pm 12.65 * \# \$ *$ \\
\hline $\begin{array}{c}\text { TGS } \\
(m g / d l)\end{array}$ & $97.81 \pm 13.44$ & $\begin{array}{l}270.50 \pm 15.52 \\
*\end{array}$ & $207.00 \pm 8.34 * \#$ & $237.75 \pm 9.808^{* \# \$}$ & $176.93 \pm 12.31 * \$ \$$ \\
\hline $\begin{array}{c}\text { LDL } \\
(m g / d l)\end{array}$ & $85.95 \pm 14.12$ & $\begin{array}{l}277.13 \pm 35.68 \\
*\end{array}$ & $\begin{array}{l}171.65 \pm 8.029 \\
\text { *\# }\end{array}$ & $231.33 \pm 14.97 * \#$ & $119.45 \pm 12.33 * \# \$$ \\
\hline $\begin{array}{l}\text { HDL } \\
(m g / d l)\end{array}$ & $43.75 \pm 4.803$ & $29.87 \pm 4.793 *$ & $35.00 \pm 3.295^{* \#}$ & $29.8750 \pm 2.35^{* \$}$ & $42.50 \pm 3.33^{\# \$ t}$ \\
\hline
\end{tabular}

Results are expressed as mean \pm SD. Significance means $p<0.05$.

(*) significant as compared to control. (\#) significant as compared to diabetic (D.M).

(\$) significant as compared to D.M+I. ( $\quad$ ) significant as compared to D.M +EPO

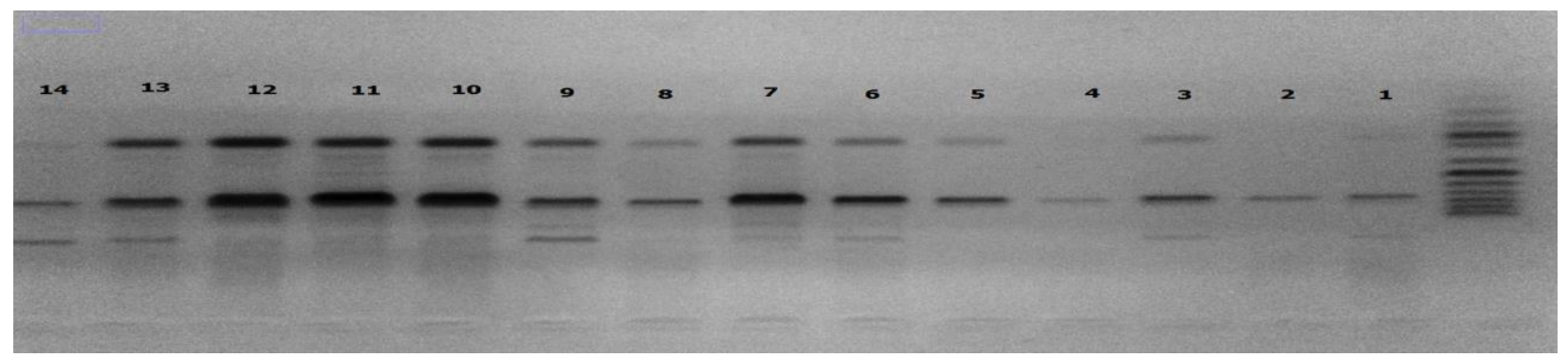

Figure (1): PCR bands: 1,2: D.M +EPO , 3-11:D.M +I +EPO , 12-14: D.M 


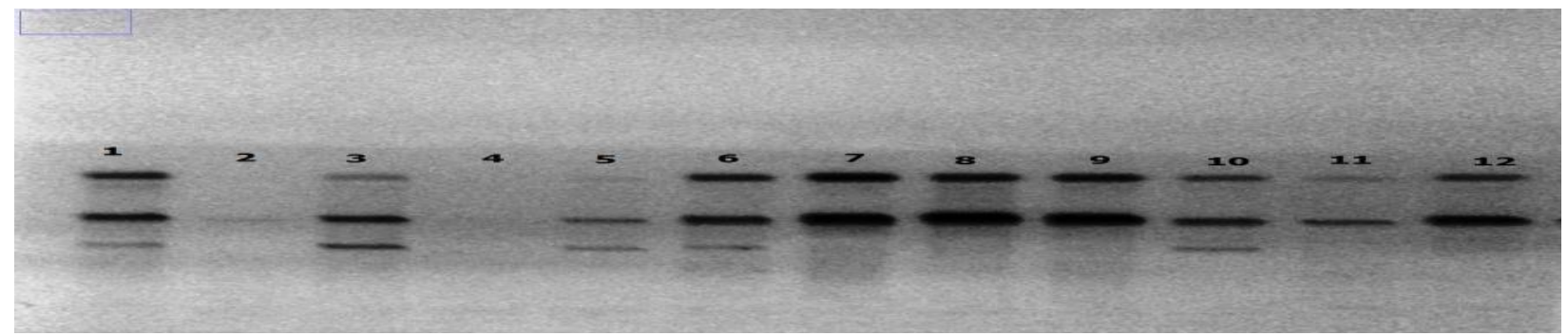

GLUT 4

Figure (2): PCR bands 1-7: D.M (control) ,8-12:D.M +I+EPO

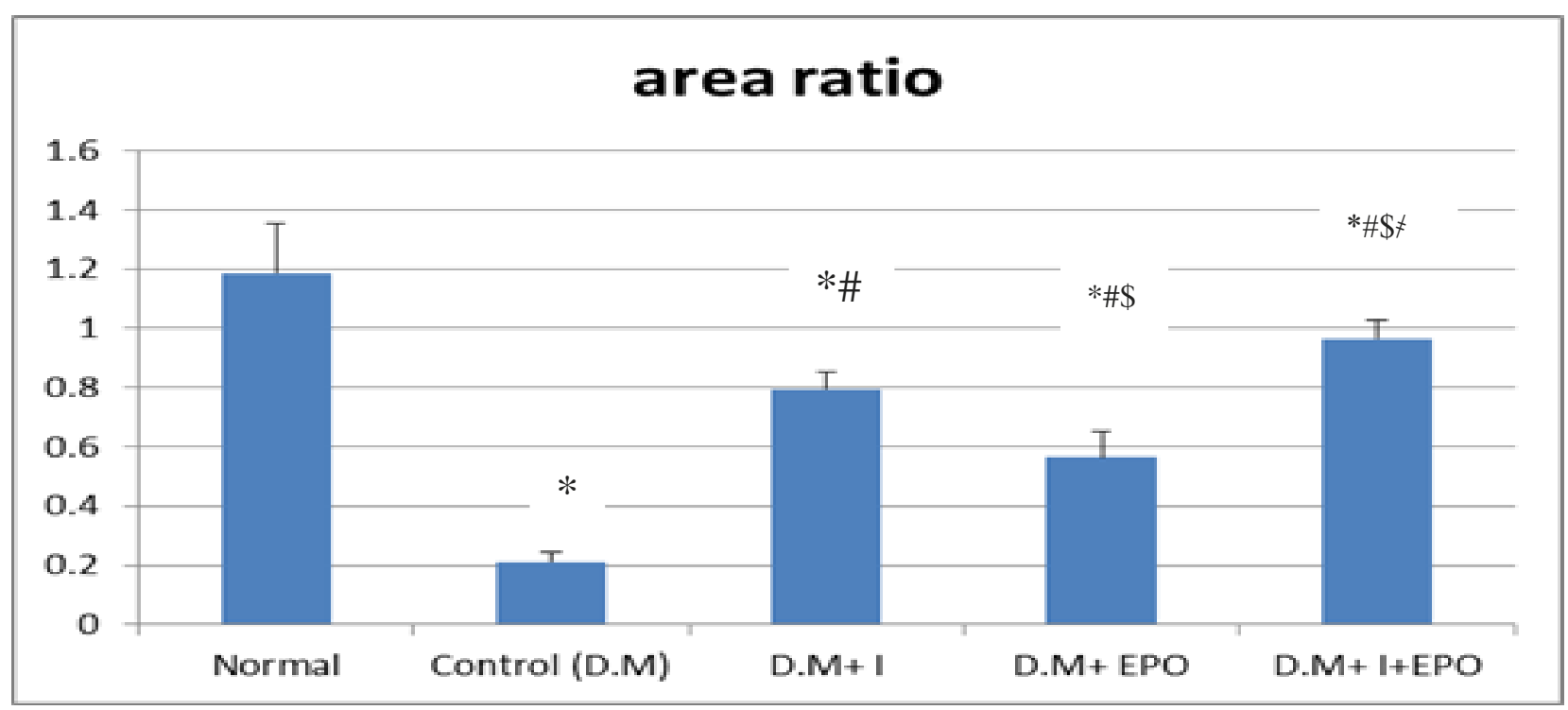

Figure (3): GLUT4 expression ratio (area ratio) in normal, diabetic, insulin treated, EPO treated, and combined treated groups (*) significant as compared to normal. (\#) significant as compared to control (D.M). (\$) significant as compared to D.M+I. (尹) significant as compared to D.M+EPO.

Table (3) shows the effect of insulin , EPO, and combined treatment on contractile properties of soleus muscle:

\begin{tabular}{|c|c|c|c|c|c|}
\hline $\begin{array}{l}\text { Groups } \\
\mathrm{N}=4\end{array}$ & $\begin{array}{c}\text { control } \\
\text { (G:I) }\end{array}$ & $\begin{array}{l}\text { (D.M) } \\
\text { (G:II) }\end{array}$ & $\begin{array}{l}\text { D.M+I } \\
\text { (G:III) }\end{array}$ & $\begin{array}{l}\text { D.M +EPO } \\
\text { (G:IV) }\end{array}$ & $\begin{array}{c}\text { D.M+I+EPO } \\
(\mathbf{G}: \mathrm{V})\end{array}$ \\
\hline $\begin{array}{l}\text { Tension before } \\
\text { fatigue (gm) }\end{array}$ & $1.787 \pm 0.070$ & $0.439 \pm 0.019 *$ & $0.771 \pm 0.020 * \#$ & $0.573 \pm 0.033^{* \#}$ & $1.182 \pm 0.093^{* \# \$ *}$ \\
\hline $\begin{array}{ll}\text { Tension } & \text { after } \\
\text { fatigue(gm) }\end{array}$ & $0.390 \pm 0.041$ & $0.192 \pm 0.014 *$ & $0.215 \pm 0.0138 *$ & $0.216 \pm 0.014^{*}$ & $0.280 \pm 0.0821^{*}$ \\
\hline $\begin{array}{l}\text { Complete fatigue } \\
\text { (sec) }\end{array}$ & $\begin{array}{l}401.25 \pm 23.9 \\
3\end{array}$ & $137.50 \pm 6.45^{*}$ & $\begin{array}{l}216.25 \pm 17.01 * \\
\#\end{array}$ & $188.75 \pm 8.53^{* \#}$ & $285.00 \pm 24.15^{* \# \mathbb{S}^{*}}$ \\
\hline Time to peak(sec) & $\begin{array}{l}0.018 \pm 0.003 \\
5\end{array}$ & $\begin{array}{l}0.160 \pm 0.0182 \\
*\end{array}$ & $0.071 \pm 0.003 * \#$ & $\begin{array}{l}0.088 \pm 0.004 * \\
\#\end{array}$ & $0.047 \pm 0.0047^{* * \$ \mathbb{S}^{*}}$ \\
\hline $\begin{array}{l}\text { Half relaxation } \\
\text { time (sec) }\end{array}$ & $\begin{array}{l}0.050 \pm 0.008 \\
1\end{array}$ & $\begin{array}{l}0.392 \pm 0.0403 \\
*\end{array}$ & $0.142 \pm 0.025^{*} \#$ & $\begin{array}{l}0.205 \pm 0.012^{* \#} \\
\$\end{array}$ & $\begin{array}{l}0.090 \pm 0.0020 * \# \\
\$ \neq\end{array}$ \\
\hline
\end{tabular}

Results are expressed as mean \pm SD. Significance means $\mathrm{p}<0.05$. (*) significant as compared to normal. (\#) significant as compared to control (D.M). (\$) significant as compared to D.M+I. ( $\quad$ ) significant as compared to D.M +EPO 


\section{Discussion}

EPO may modify several health factors that could modify the onset of many diseases. Previous researches have shown that EPO injection may reduce hyperglycemia in diabetic rats through activation of EPO receptors (23). On the other hand, diabetes-related changes in skeletal muscles is a less studied complication of poorly controlled diabetes, in spite that, it is a common condition that is characterized by decrease in muscle mass, weakness, and an overall reduced physical capacity (24). Therefore, the aim of The present study was to examine the possible role of EPO hormone solely or in combination with insulin in improving diabetes-induced derangement in metabolic and contractile changes in soleus skeletal muscle in Type 1 D.M rat model.

The study demonstrated that EPO treatment (200 $\mathrm{U} / \mathrm{kg}$, three times a week for 4 weeks) was effective in reducing FBG and serum insulin, in STZinduced experimental diabetic rats. These results was in agreement with previous study that explain the results by the EPO effect in normalizing the state and the quantity of mitochondria and golgi apparatus, and increased the number of insulin secreting granules in the pancreatic $\beta$-cells (25). Another explanation may be due to antioxidantlike action of EPO (26) which may be due to upregulating hemoglobin oxidase-1 (27), and increasing RBCs number in the circulation, thus reducing cellular oxidative stress (28).

Concerning lipid metabolism, EPO causes significant decrease in serum triglyceride, cholesterol, LDL, with significant increase in HDL
.These results was in accordance with previous study(29). The significant decrease of triglyceride level may be related to an improved response to insulin, science increased insulin resistance was known to be associated with diminished lipoprotein lipase activity, while the triglyceride production remains normal and thus results in hypertriglyceridemia (30). The increased serum HDL levels may be attributed to improvement in tissue oxygenation which increases activity of ATP-binding cassette transporter (ABCA1) or other enzymes involved in maturation of HDL and increase its levels ( 31 ).

Regarding contractile function, contraction of soleus muscle (Type 1 or slow twitch or red muscle) in diabetic rats, as observed in the study , showed significant decrease in isometric contraction (muscle tension) as compared to control before and after fatigue. This was previously illustrated by ( $32 \& 33$ ). Normal skeletal muscles are able to produce maximum force of contraction of higher magnitude than diabetic muscle due to better fuel supply and its utilization along with low oxidative stress and lactate levels (34).

Diabetic muscle showed more rapid fatigue than control one and than groups treated with insulin or EPO or both, this was cleared in this study by measuring time taken by the muscle to complete fatigue. (35), illustrated that repeated stimulation of diabetic muscle leads to reduced glycogen stores and increase lactate level, exhausted their ATP supply significantly greater than normal group. Muscle fatigue was measured as a decrease in maximum force of contraction due to the 
repeated contractions at tetanic frequencies. Significant fatigue (early fatigue) was observed in the study in diabetic muscle. This was explained by (32), who illustrated pronounced fatigue in soleus diabetic muscle when compared to normal, and explained these by alternation in $\mathrm{Ca}++$ homeostasis and compromised muscle oxygenation following muscle contractions. (36) reported that, soleus muscle of STZ diabetic rats showed decline in the level of sarcoplasmic reticulum $\mathrm{Ca}+2-$ ATPase protein levels. So, resolution of the oxygen dysregulation, and the role of $\mathrm{Ca}+2$ in those signaling processes will constitute an important goal in combating diabetes-induced skeletal muscle dysfunction. As represented by animal model, the peripheral circulation is profoundly dysfunctional in diabetes (37), increasing the possibility that acute and chronic diabetes-induced muscular deficits at least by impaired oxygen transport. Contractile function is sensitive to increased or decreased blood oxygen content and muscle oxygen supply (38). hypoxia exacerbates intracellular disorders in the form of increase free ADP, decrease intracellular phosphocreatine(37).

The study also reveald that, time taken by the muscle to reach peak and time taken to relax 50\% was significantly increased in diabetic compared to control group. Time to peak depends on the velocity of $\mathrm{ca}^{+2}$ release from sarcoplasmic reticulum , but half relaxation time depends upon the rapidity of $\mathrm{ca}^{+2}$ pumping from the sarcoplasm to the sarcoplasmic reticulum (39). Calcium handling characteristics are altered in the STZ-diabetic muscle, so longer rise and half-relaxation times of single muscle twitches occur (1).
Insulin treatment produced significant improvement in muscle tension, half relaxation time and time to peak when compared to diabetic group .This is due to the important role of insulin in control glucose uptake, activate the pathway for protein synthesis and by inhibiting degradation of skeletal muscle protein (40). EPO treatment also, showed significant increase in muscle tension when compared to diabetic group, which illustrated in a previous study done by (41), who explained this significant improvement in contractile function of soleus muscle when compared to diabetic, due to the role of EPO in protecting myoblasts against hypoxia-induced apoptosis . Another study illustrated that EPO supplementation alone or coupled with enhanced EPO-R expression promoted rat myoblast survival (42). It has been suggested that, local EPO treatment increases rat soleus muscle regeneration and strength following mechanically induced injury, a response associated with increased proliferating satellite cells numbers (40). A study in skeletal muscle from EPOdeficient mice showed increases in genes related to muscle hypoxia, proteolysis, cell death and apoptosis as well as reductions in genes involved in glycolysis and mitochondrial function. These findings support the hypothesis that EPO has a protective effect in skeletal muscle. (43). Nachbauer et al.,2012 claimed that prolonged EPO administration increases muscle capillary density and contribute to improve the motor function.

A decrease in insulin-mediated glucose uptake caused by a lower levels of GLUT4 expression has been documented in diabetic skeletal muscle, a major site for glucose disposal (45). The present study revealed a significant increase in GLUT4 
expression in the insulin treated group. The effect of insulin on GLUT4 translocation is mediated through intracellular signaling pathway through tyrosine phosphorylation of insulin receptor substrate-1 (IRS-1) associated with phosphatidylinositol 3-kinase (PI3K), phosphorylation of AKT/PKB and TBC14D/AS160 which is a down stream target of AKT in the distal insulin signaling pathway (46). GLUT 4 expression was also improved in EPO treated group in the study. Despite the significant role of GLUT4 in glucose metabolism, the molecular mechanisms underlying the transcriptional regulation of GLUT4 are poorly understood (47). One of the marked signals associated with EPORs for glucose homeostasis is AMPK (48). EPO treatment might increase the phosphorylation of AMPK in muscles..It has been established that activation of AMPK may enhance GLUT4 levels (49).

The greater improvement was obtained when EPO combined with insulin, this may be due to synergistic effect of both drugs on all parameters, or due to increase blood supply and $\mathrm{O} 2$ to the tissue by the effect of EPO that enhance the action of insulin. But the precise mechanism still need further researche.

\section{conclusion}

From the previous results, it is possible to conclude that, EPO may be benfecial in managing diabetic disorders particularly skeletal muscle dysfunction . EPO injection reduce hyperglycemia and hyperlipidemia in diabetic rats and upregulate GLUT 4 expression in skeletal muscle, with a better effect when it is used in combination with insulin. EPO receptor will be a good target for the development of antihyperglycemic agent(s) in the future.

Recommendations: EPO could offer a great promise as a therapeutic strategy in addition to insulin in patients with type 1 diabetes to improve skeletal muscle functions and myopathy.

\section{Acknowledgements}

We would like to express our sincere gratitude to the laboratory technicians for their valuable efforts.

\section{References}

\section{Krause MP., Riddell MC., Gordon CS., Imam} SA., Cafarelli E., \& Hawke TJ. Diabetic myopathy differs between Ins2Akita /- and streptozotocin-induced Type 1 diabetic models. Journal of Applied Physiology, 106(5), 1650-1659. doi:10.1152/japplphysiol.91565.2008, 2009

2. Snow LM., Lynner CB., Nielsen EM., Neu HS., \& Thompson LV. Advanced Glycation End Product in Diabetic Rat Skeletal Muscle in vivo. Pathobiology, $\quad$ 73(5), 244-251. doi:10.1159/000098210, 2007

\section{Snow LM., Fugere NA., \& Thompson LV.} Advanced Glycation End-Product Accumulation and Associated Protein Modification in Type II Skeletal Muscle With Aging. The Journals of Gerontology Series A: Biological Sciences and Medical Sciences, 62(11), 1204-1210. doi:10.1093/gerona/62.11.1204, 2006

\section{Cotter M., Cameron N., Robertson S., \&}

Ewing I. Polyol pathway-related skeletal muscle contractile and morphological abnormalities in 
diabetic rats. Exp Physiol Experimental Physiology, $78(2)$,

139-155.

doi:10.1113/expphysiol.1993.sp003675, 1993

5. Brownlee M. The Pathobiology of Diabetic Complications: A Unifying Mechanism. Diabetes, 54(6), 1615-1625. doi:10.2337/diabetes.54.6.1615, 2005

6. Herman M A. \& Kahn BB. Glucose transport and sensing in the maintenance of glucose homeostasis and metabolic harmony. Journal of Clinical Investigation, 116(7), 1767-1775. doi:10.1172/jci29027, 2006

7. Chen, Z. Y., Asavaritikrai, P., Prchal, J. T., and Noguchi, C. T. Endogenous erythropoietin signaling is required for normal neural progenitor cell proliferation. J. Biol. Chem. 282, 25875-25883 2,2007

8. Ogilvie, M., Yu, X., Nicolas-Metral, V., Pulido, S. M., Liu, C., Ruegg, U. T., and Noguchi, C. T. Erythropoietin stimulates proliferation and interferes with differentiation of myoblasts. J. Biol. Chem. 275, 39754-39761, 2000

9. Yu, X., Shacka, J. J., Eells, J. B., SuarezQuian, C., Przygodzki, R. M., Beleslin-Cokic, B., Lin, C. S., Nikodem, V. M., Hempstead, B., Flanders, K. C., Costantini, F., and Noguchi, C. $\mathbf{T}$.Erythropoietin receptor signalling is required for normal brain development. Development 129, 505516,2002

10. Zhang Y, Wang L, Dey S, Alnaeeli M, Suresh S, Rogers H, Teng $R$ and Noguchi CT. Erythropoietin action in stress response, tissue maintenance and metabolism. Int J Mol Sci 15: 10296-10333, 2014. Choi D, Retnakaran R and Woo M: The extra-hematopoietic role of erythropoietin in diabetes mellitus. Curr Diabetes Rev 7: 284-290, 2011

11. Dimitrijevic ZM, Cvetkovic TP, Djordjevic VM, Pavlovic DD, Stefanovic NZ, Stojanovic IR, Paunovic GJ and Velickovic-Radovanovic RM .How the duration period of erythropoietin treatment influences the oxidative status of hemodialysis patients. Int J Med Sci 9: 808-815, 2012

12. Nairz M, Sonnweber T, Schroll A, Theurl I and Weiss G. The pleiotropic effects of erythropoietin in infection and inflammation. Microbes Infect 14: 238-246, 2012.

13. Chen S, Li J, Peng H, Zhou J and Fang $H$. Administration of erythropoietin exerts protective effects against glucocorticoid-induced osteonecrosis of the femoral head in rats. Int J Mol Med 33: 840-848, 2014.

14. Stoyanoff TR, Todaro JS, Aguirre MV, Zimmermann MC and Brandan NC. Amelioration of lipopolysaccharide-induced acute kidney injury by erythropoietin: Involvement of mitochondria-regulated apoptosis. Toxicology 318: 13-21, 2014.

15. Suzuki, N., Ohneda, O., Takahashi, S., Higuchi, M., Mukai, H. Y., Nakahata, T., Imagawa, S., and Yamamoto, M. Erythroidspecific expression of the erythropoietin receptor rescued its null mutant mice from lethality. Blood 100, 2279-2288, 2002

16. Tuzcu A, Bahceci M, Yilmaz E, Bahceci S, Tuzcu S. The comparison of insulin sensitivity in non-diabetic hemodialysis patients treated with and without recombinant human erythropoietin. Horm Metab Res.;36(10):716-720, 2004 
17. Ünlüçerçi Y., Bekpinar S., Gürdöl F., \& Seferoğlu G. A study on the relationship between homocysteine and diabetic nephropathy in rats. Pharmacological Research, 45(3), 249-252. doi:10.1006/phrs.2001.0942, 2002

18-Foskett A., Alnaeeli M., Wang L., Teng R., \& Noguchi CT. The Effects of Erythropoietin Dose Titration during High-Fat Diet-Induced Obesity. Journal of Biomedicine and Biotechnology, $\quad 2011, \quad$ 1-8. doi:10.1155/2011/373781, 2011

19. Im S., Kwon S., Kang S., Kim T., Kim H., Hur M., et al. Regulation of GLUT4 gene expression by SREBP-1c in adipocytes. Biochem. J. Biochemical Journal, 399(1), 131-139. doi:10.1042/bj20060696, 2006

20. Zhang XF1, \& Tan BK. Effects of an ethanolic extract of Gynura procumbens on serum glucose, cholesterol and triglyceride levels in normal and streptozotocin-induced diabetic rats. Singapore Med J 41(1):9-13, 2000

21. Patel R., Shah P., Deshpande S., Shah G., \& Gohil P. Fructose diet and low dose streptozotocin treatment induces the development of diabetic nephropathy in rats. Oriental Pharmacy and Experimental Medicine Orient Pharm Exp Med, 15(4), 305-312. doi:10.1007/s13596-0150193-7, 2015

22. Liu Y., Huo X., Pang X., Zong Z., Meng X., \& Liu G. Musclin Inhibits Insulin Activation of Akt/Protein Kinase B in Rat Skeletal Muscle. Journal of International Medical Research, 36(3), 496-504,2008
23. Maiese K. Erythropoietin and diabetes mellitus. World Journal of Diabetes WJD, 6(14), 1259. doi:10.4239/wjd.v6.i14.1259, 2015

\section{Andersen H., Schmitz O., \& Nielsen S .}

Decreased isometric muscle strength after acute hyperglycaemia in Type 1 diabetic patients. Diabetic Medicine Diabet Med, 22(10), 1401-1407. doi:10.1111/j.1464-5491.2005.01649.x, 2005

25. LI-Na Chen, Qiang Sun, Shu-Qing Liu, Haohu, Juanlv, Wen-Jun JI, Meng Wang, Ming-Xia Chen and Jun Zhou. Erythropoietin improves glucose metabolism and pancreatic $\beta$-cell damage in experimental diabetic rats. MOLECULAR MEDICINE REPORTS 12: 53915398, 2015

26. Rjiba-Touati K., Ayed-Boussema I., Guedri Y., Achour A., Bacha H., \& Abid-Essefi S. Effect of recombinant human erythropoietin on mitomycin $\mathrm{C}$-induced oxidative stress and genotoxicity in rat kidney and heart tissues. Human \& Experimental Toxicology, 35(1), 53-62. doi:10.1177/0960327115577521, 2015

27. Luo YH, Li ZD, Liu LX and Dong GH. Pretreatment with erythropoietin reduces hepatic ischemia-reperfusion injury. Hepatobiliary Pancreat Dis Int 8: 294-299, 2009.

28. Liu N, Tian J, Wang W, Cheng J, Hu D and Zhang J. Effect and mechanism of erythropoietin on mesenchymal stem cell proliferation in vitro under the acute kidney injury microenvironment. Exp Biol Med (Maywood) 236: 1093-1099, 2011

29. Carol A. Pollock, Roger WYNDHAM, Paul V. Collett, Graham Elder, Michiel J. Field, Steven Kalows KI, James R. Lawrence, David A. Waugh, and Charlis R.P. George. Effects of 
erythropoietin therapy on the lipid profile in endstage renal failure Kidney International, Vol. 45, pp. 897—902, 1994

30. Khedr E, El-Sharkawy M, Abdulwahab S, Eldin EN, Ali M, et al. Effect of recombinant human erythropoietin on insulin resistance in hemodialysis patients. Hemodial Int 13: 340-6. 2009

31. Kruit JK., Kremer PH., Dai L., Tang R., Ruddle P., de Haan W., et al. Cholesterol efflux via ATP-binding cassette transporter A1 (ABCA1) and cholesterol uptake via the LDL receptor influences cholesterol-induced impairment of beta cell function in mice. Diabetologia 53:1110-19, 2010

32. Eshima H., Poole DC., \& Kano Y. In vivo Ca 2 buffering capacity and microvascular oxygen pressures following muscle contractions in diabetic rat skeletal muscles: Fiber-type specific effects. American Journal of Physiology - Regulatory, Integrative and Comparative Physiology Am J Physiol Regul Integr Comp Physiol, 309(2). doi:10.1152/ajpregu.00044,2015

33. Brotto M., Brotto L., Jin J., Nosek TM., \& Romani A. Temporal Adaptive Changes in Contractility and Fatigability of Diaphragm Muscles from Streptozotocin-Diabetic Rats. Journal of Biomedicine and Biotechnology, 2010, 1-8. doi:10.1155/2010/931903,2010

34. Aleem SB. \& Hussain MM. Levo-carnitine supplementation normalizes skeletal muscle functions in type 2 diabetic rats. Pakistan. Int $J$ Diabetes \& Metab;( 21)1-8, 2012

35. Henriksson J. Effects of Physical Training on the Metabolism of Skeletal Muscle. Diabetes Care,
15(11),

1701-1711.

doi:10.2337/diacare.15.11.1701, 1992

36. Racz G, Szabo A, Ver A, \& Zador E. The slow sarco/endoplasmic reticulum Ca2 -ATPase declines independently of slow myosin in soleus muscle of diabetic rats. Acta Biochim Pol56: 487 493, 2009

\section{Behnke BJ., Kindig CA., Mcdonough P.,} Poole DC., \& Sexton WL. Dynamics of microvascular oxygen pressure during restcontraction transition in skeletal muscle of diabetic rats. American Journal of Physiology - Heart and Circulatory Physiology, 283(3). doi:10.1152/ajpheart.00059.2002, 2002

38. Amann M., Eldridge MW., Lovering AT., Stickland MK., Pegelow DF., \& Dempsey JA. Arterial oxygenation influences central motor output and exercise performance via effects on peripheral locomotor muscle fatigue in humans. The Journal of Physiology, 575(3), 937-952. doi:10.1113/jphysiol.2006.113936, 2006

39. Canato M., Scorzeto M., Giacomello M., Protasi F., Reggiani C., \& Stienen GJ. Massive alterations of sarcoplasmic reticulum free calcium in skeletal muscle fibers lacking calsequestrin revealed by a genetically encoded probe. Proceedings of the National Academy of Sciences, 107(51), 22326-22331. doi:10.1073/pnas.1009168108,2010

40. Krause MP., Riddell MC., \& Hawke TJ. Effects of type 1 diabetes mellitus on skeletal muscle: Clinical observations and physiological mechanisms. Pediatric Diabetes, 12(4pt1), 345364. doi:10.1111/j.1399-5448.2010.00699.x, 2010 
41. Rotter R., Menshykova M., WinklerT.,Matziolis G.,Stratos I.,Schoen M., et al. Erythropoietin improves functional and histological recovery of traumatized skeletal muscle tissue. J. Orthop. Res.26, 1618-1626. doi: 10.1002/jor.20692, 2008

42. JiaY.,Warin R.,Yu X.,Epstein R., and Noguchi CT. Erythropoietin signaling promotes transplanted progenitor cell survival.FASEB J.23, 3089-3099. doi:10.1096/fj.09-130237, 2009

43. Mille-Hamard L., Billat V L., Henry E., Bonnamy B., Joly F., Benech P., et al. Skeletal muscle alterations and exercise performance decrease in erythropoietindeficient mice: a comparative study.BMC Med. Genomics 5:29. doi:10.1186/1755-8794-5-29, 2012

doi:10.1177/147323000803600314, 2008

44. Nachbauer W., Boesch S., Reindl M.,Eigentler A., Hufler K., Poewe W., et al. Skeletal muscle involvement in friedreich ataxia and potential effects of recombinant human erythropoietin administration on muscle regeneration and neovascularization.J. Neuropathol.Exp. Neurol. 71, 708-715. doi:10.1097/NEN.0b013e31825fed76, 2012

45. McGee SL, van Denderen BJ, Howlett KF, et al. AMP-activated protein kinase regulates GLUT4 transcription by phosphorylating histone deacetylase 5. Diabetes.;57(4):860-867, 2008

46. Maran A., Pavan P., Bonsembiante B., Brugin E., Ermolao A., Avogaro A., \& Zaccaria M. Continuous Glucose Monitoring Reveals Delayed Nocturnal Hypoglycemia After Intermittent High-Intensity Exercise in Nontrained Patients with Type 1 Diabetes. Diabetes
Technology \& Therapeutics, 12(10), 763-768. doi:10.1089/dia.2010.0038, 2010

47. Cheng J., Niu H., Chang C., Niu C., \& Lee K. Erythropoietin ameliorates hyperglycemia in type 1-like diabetic rats. Drug Design, Development and Therapy, 1877. doi:10.2147/dddt.s105867, 2016

48. Maiese K. Erythropoietin and diabetes mellitus. World J Diabetes.;6(14):1259-1273, 2015

49. Rodríguez-Calvo R., Vázquez-Carrera M., Masana L., \& Neumann D. AICAR Protects against High Palmitate/High Insulin-Induced Intramyocellular Lipid Accumulation and Insulin Resistance in HL-1 Cardiac Cells by Inducing PPAR-Target Gene Expression. PPAR Research, 2015, 1-12. doi:10.1155/2015/785783, 2015 